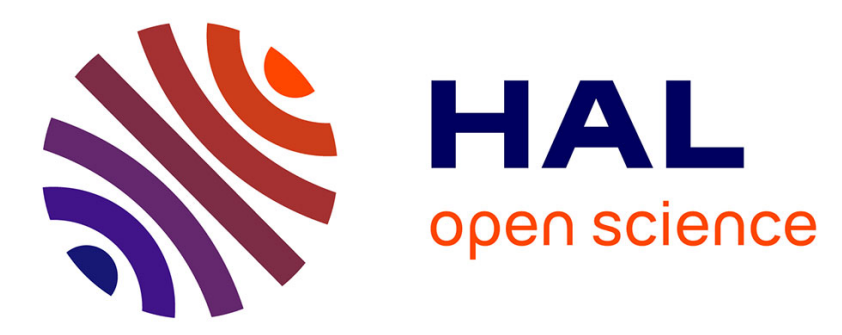

\title{
Early polysynaptic potentiation recorded in the dentate gyrus during an associative learning task
}

Franck A Chaillan, Bruno Truchet, François S Roman, Bernard

Soumireu-Mourat

\section{- To cite this version:}

Franck A Chaillan, Bruno Truchet, François S Roman, Bernard Soumireu-Mourat. Early polysynaptic potentiation recorded in the dentate gyrus during an associative learning task. Neuroscience, 1999, 94, pp.443 - 451. 10.1016/S0306-4522(99)00304-8 . hal-01475569

\author{
HAL Id: hal-01475569 \\ https://hal.science/hal-01475569
}

Submitted on 23 Feb 2017

HAL is a multi-disciplinary open access archive for the deposit and dissemination of scientific research documents, whether they are published or not. The documents may come from teaching and research institutions in France or abroad, or from public or private research centers.
L'archive ouverte pluridisciplinaire HAL, est destinée au dépôt et à la diffusion de documents scientifiques de niveau recherche, publiés ou non, émanant des établissements d'enseignement et de recherche français ou étrangers, des laboratoires publics ou privés. 


\title{
EARLY POLYSYNAPTIC POTENTIATION RECORDED IN THE DENTATE GYRUS DURING AN ASSOCIATIVE LEARNING TASK
}

\author{
F. A. CHAILLAN, ${ }^{*}$ B. TRUCHET, F. S. ROMAN and B. SOUMIREU-MOURAT \\ Laboratoire de Neurobiologie des Comportements, UMR 6562, Université de Provence, I.B.H.O.P., \\ Traverse Charles Susini, 13388 Marseille cedex 13, France
}

\begin{abstract}
In this report, we investigated the electrophysiological dynamics of the neuronal circuit including the dentate gyrus during an associative task. A group of rats was trained to discriminate between a patterned electrical stimulation of the lateral olfactory tract, used as an artificial cue associated with a water reward, and a natural odor associated with a light flash. Polysynaptic field potential responses, evoked by a single electrical stimulation of the same lateral olfactory tract electrode, were recorded in the molecular layer of the ipsilateral dentate gyrus prior to and just after each training session. An increase in this response was observed when a significant discrimination of the two cues began. A positive correlation was found between the change in the polysynaptic potentiation and behavioral performances. The onset latency of the potentiated polysynaptic response was $35-45 \mathrm{~ms}$. When a group of naive animals was pseudoconditioned, no change in field potential was observed.

These results are consistent with the hypothesized dynamic activation of the dentate gyrus early in the making of association, allowing gradual storage of associative information in a defined set of synapses. Moreover, the onset latency of the potentiated response suggests the existence of reactivating hippocampal loops during the processing of associative information. (C) 1999 IBRO. Published by Elsevier Science Ltd.
\end{abstract}

Key words: polysynaptic potentiation, dentate gyrus, associative learning.

Memory formation is considered to be the result of modifications to neuronal activity in vast and complex neural networks. ${ }^{6}$ The existence of specific electrical reverberant circuits, thought to maintain information, is not able to account for the long-term storage of that information. $3,30,43$ Different theories postulate that cellular modifications are needed to conserve a stable trace. The phenomenon of longterm potentiation (LTP) is a likely candidate for this type of cellular modification. LTP is a long-term enhancement of monosynaptic excitatory transmission elicited by short, high-frequency electrical stimulation of the afferent pathway. This phenomenon was first described in the hippocampus, ${ }^{4,5} \mathrm{a}$ part of the medial temporal lobe. ${ }^{39}$ Since the first report of hippocampal LTP, numerous studies have replicated the findings and characterized many of the underlying mechanisms. Although most of the LTP research focuses on the hippocampus, the phenomenon is not specific to this structure. Many studies have reported expression of LTP in different parts of the mammalian brain, including the prefrontal cortex, ${ }^{24}$ visual cortex, ${ }^{1}$ piriform (olfactory) cortex, ${ }^{35,36,40}$ superior colliculus $^{32}$ and olfactory bulb. ${ }^{12}$

In vivo and in vitro studies have shown that patterned electrical stimulations alone are able to elicit LTP in the hippocampus and in many other brain areas. ${ }^{34}$ In the piriform (olfactory) cortex, additional conditions seem to be needed to be observed. LTP is elicited in the piriform cortex only when patterned electrical stimulation, applied to the lateral olfactory tract (LOT), and reward were associated in a learning context. ${ }^{35}$ In previous studies, Roman et al. ${ }^{36}$ showed that LTP in the piriform cortex was gradual and appeared only

\footnotetext{
*To whom correspondence should be addressed. Fax: + 33-04-91-98-28-97. E-mail address: nbc@newsup.univ-mrs.fr (F. A. Chaillan)

Abbreviations: DG, dentate gyrus; LOT, lateral olfactory tract; LTP, longterm potentiation; $\mathrm{O}-$, negative natural odor; OMS, olfactomimetic stimulation; PEP, polysynaptic evoked potential.
}

when there was significant discrimination between the two cues (in this case, patterned stimulation versus natural odor). The authors found a positive correlation between the improvement in behavioral performance and the increase in the slope of the monosynaptic responses recorded in the olfactory cortex. This correlation suggests that the gradual learning of the meaning of the cues led to a gradual change in cortical synapses (i.e. in the piriform cortex). Thus, it was hypothesized that this learning condition will allow the release of an active suppression on the target cells in the piriform cortex in order to modify specific synapses supporting the odor-reward association. ${ }^{35}$ In addition, the patterned stimulation alone, without any learning context, elicited a long-term depression of the monosynaptic responses. ${ }^{36}$ Moreover, in piriform cortex slices, short-term potentiation and LTP of the population synaptic responses can be readily observed. ${ }^{13}$ Finally, bilateral lesion of the horizontal diagonal band of Broca, a relay between the hippocampus, ${ }^{15,17}$ the piriform cortex ${ }^{27,47}$ and the olfactory bulb, or neonatal $\gamma$-ray irradiation of the hippocampus ${ }^{7}$ results in a severe deficit on this olfactory task. ${ }^{37}$ Taken together, these reports suggest that limbic circuits related to the olfactory system play an important role in this active suppression. Activation of these circuits will allow an increase in synaptic efficacy by an LTP phenomenon in a specific set of synapses in the piriform cortex.

Neuroanatomical evidence indicates that the entorhinal cortex, a secondary olfactory cortex, is directly connected to the olfactory bulb via the LOT, and to the piriform cortex via pyramidal cell axon collaterals. ${ }^{45}$ Moreover, electrophysiological data have shown that ablation of the lateral entorhinal cortex abolishes the polysynaptic evoked potential (PEP) elicited in the dentate gyrus (DG) by stimulation of the LOT. ${ }^{44}$ This is not the case when the medial entorhinal cortex is destroyed. This observation suggests that the lateral entorhinal cortex is specifically involved in the transmission of the 
olfactory information to the hippocampus through the lateral perforant pathways. ${ }^{45}$

In this report, combining electrophysiological and behavioral experiments, the dynamics of the involvement of these limbic circuits during the learning and memory of an associative task were studied. The eventual electrophysiological observation in these circuits correlated to behavioral performance will indicate the chronology of their involvement in the modification of synapses in the piriform cortex.

\section{EXPERIMENTAL PROCEDURES}

Animals

Male Sprague-Dawley rats (Iffa-Credo, France), weighing 300$350 \mathrm{~g}$ at the start of the experiment, served as subjects. They were housed in an environmentally controlled vivarium on a $12-\mathrm{h} / 12-\mathrm{h}$ light-dark cycle, with light on at 6.30 a.m.

Upon arrival, animals were handled once a day. They were weighed daily beginning three days before the first training session. All subjects were deprived of water $48 \mathrm{~h}$ before the first training session. On the following days, the rats were given water ad libitum for $30 \mathrm{~min}$ per day at $6.30 \mathrm{p} . \mathrm{m}$. All efforts were made to minimize animal suffering and to reduce the number of animals used.

\section{Surgery}

All animals were implanted unilaterally under sodium pentobarbital $(60 \mathrm{mg} / \mathrm{kg}$, i.p.) anesthesia. A bipolar $(125 \mu \mathrm{m})$ stainless steel stimulating electrode insulated except at the tip was lowered into the LOT. It was stereotaxically positioned at $3.7 \mathrm{~mm}$ anterior and $3.2 \mathrm{~mm}$ lateral to bregma. A twisted bipolar platinum recording electrode $(90 \mu \mathrm{m})$ with beveled tips was positioned in the ipsilateral DG, $4 \mathrm{~mm}$ posterior and $2 \mathrm{~mm}$ lateral to bregma, and approximately $3 \mathrm{~mm}$ below the brain surface. ${ }^{33}$ Differential records were made between the two tips with respect to a common reference. The distance between the two tips was $150-200 \mu \mathrm{m}$. The lower positive tip was positioned at the granule cell layer level. The final position was made under electrophysiological control with LOT stimulation to produce a PEP in the DG. A small screw on the contralateral occipital skull served as a ground. Electrodes were attached to a male plastic connector (GM12, Phymep), which was fixed to the skull with acrylic dental cement. The animals were then returned to their home cage.

\section{Conditioning apparatus}

The experiments were conducted in a wire-mesh cage $(30 \mathrm{~cm} \times 30 \mathrm{~cm} \times 50 \mathrm{~cm})$. A conical odor port $(1.5 \mathrm{~cm}$ diameter, $0.5 \mathrm{~cm}$ above the floor) was drilled horizontally through a triangular wedge of Plexiglas, mounted in one corner of the cage. A circular ( $1 \mathrm{~cm}$ diameter) water port in the shape of a well was located directly above the odor port. Water port responses were monitored by a photoelectric circuit. Two flashlight bulbs, which could be turned on and off as conditions required, were placed outside the cage $10 \mathrm{~cm}$ above the floor, one on each side of the odor and water ports.

Individual odor was delivered by forcing clean air ( 0.7 bars) through one of two 1000-ml Ehrlenmeyer flasks that contained $500 \mathrm{ml}$ of water mixed $(2 \%)$ with one of the chemical or natural odorants (strawberry, lemon or pineapple; Sanofi Bio Industries) and $500 \mathrm{ml}$ of air. Nonodorized air could be delivered by passing air through a flask that contained only water. Odorized and clean air streams were sent individually through tubes, which were passed through the back of a sound-attenuating chamber and attached to the odor port. Odor clearance was achieved by passing a clear air stream throughout the time interval between two successive trials. Odorized and clean air resulted in a $31 / \mathrm{min}$ air stream at the odor port. Water was delivered using a gravity-feed system and was passed through a valve which, when opened, allowed $0.1 \mathrm{ml}$ of water to be released into the water port.

All procedural and behavioral events where controlled and recorded by microcomputer.

Inside the cage, a female plastic connector (GF12, Phymep) was attached to a multiwire lead from a rotating commutator, which in turn was connected to an SMP-300 programmable stimulator
(BIOLOGIC, with modifications) and recording equipment (Grass preamplifier Model P 15 and Hewlett Packard microcomputer).

\section{Discrimination training}

In Experiment 1, rats $(n=11)$ with indwelling electrodes were trained to discriminate high-frequency electrical stimulations of the LOT (positive cue) and a natural odor (negative cue), using a successive Go-NoGo paradigm. ${ }^{35}$ When the positive cue was presented for $10 \mathrm{~s}$, animals had to approach the odor and water ports, which were in one corner of the cage. This approach interrupted a light beam, resulting in a $0.1-\mathrm{ml}$ water reward. During the negative natural odor presentation, a correct response required not interrupting the light beam, which if interrupted, resulted in a 10-s presentation of a nonaversive light and no water reward. There was a 15-s inter-trial interval before the next trial. If the rats responded during the intertrial interval, an additional $10 \mathrm{~s}$ delayed the next trial and was added whenever the rats returned to this corner, at a time when a new trial should have begun. Clean air flowed continuously into the cage from the odor port, except during the negative odor presentation. Individual trials were presented in a quasi-random fashion and never for longer than $10 \mathrm{~s}$. A trial started $15 \mathrm{~s}$ after termination of either water or light delivery and when the subject left the corner. A daily session of $30 \pm 0.5 \mathrm{~min}$ consisted of 60 trials with an inter-trial interval of $15 \mathrm{~s}$. Animals were tested every day for five days between $8.00 \mathrm{a} . \mathrm{m}$. and 2.00 p.m.

Correct responses were "Go" to interrupt the light beam for the positive cue before the end of the 10-s presentation, and "NoGo" for the negative odor during the 10-s presentation. Incorrect responses were "Go" to interrupt the light beam before the 10-s presentation for the negative odor and "NoGo" to not interrupt the light beam during the 10-s presentation for the positive cue. Animal performance was defined using three criteria. (1) The percentage of correct responses, which is the number of correct responses for both positive and negative cues, and was expressed as a percentage of the total number of cue presentations, thereby providing a global estimate of performance, with the learning criterion at $80 \pm 5 \%$ correct responses. The formula to calculate the "percentage correct" is: $(\mathrm{CR} / n) \times 100$, where $\mathrm{CR}$ is the number of correct responses and $n$ the number of trials. (2) The response latency for both cues is the time (seconds) elapsed between cue presentation and an eventual response; thus, correct and incorrect responses were pooled for both cues, respectively, divided by 30 trials. (3) The differences between latencies, i.e. negative odor latency minus positive cue latency, for the first and last 10 trials. For each session, the percentage of correct responses and latencies was also analysed for the first and last 10 trials. Across all sessions, the rats learned to associate the stimuli with their respective rewards, i.e. to respond for the positive olfactomimetic stimulation (OMS + ) to obtain the water reward and to not respond for the negative natural odor $(\mathrm{O}-)$. The animals have a tendency to respond for both cues and sometimes the animals respond for $\mathrm{O}-$ even when they master the associations. For this reason, the percentage of correct responses for $\mathrm{O}-$ and moreover the global percentage of correct responses for both cues cannot reach $100 \%$. Accordingly, if one animal responds only once for $\mathrm{O}-$, the response latency for $\mathrm{O}-$ cannot reach $10 \mathrm{~s}$, which does not mean that the animals could not master the learning, but on the contrary that they pay attention to the $\mathrm{O}-$ cue.

Animals were allowed to recover for two weeks after electrode implantation. Four days before the first training session, implanted animals were connected to the switch so that they could get used to moving easily in the training apparatus. Two days before the first training session, 20 single electrical biphasic test pulses (one every $15 \mathrm{~s})$ were delivered to the LOT. The PEPs were recorded in the granular cell layer of the ipsilateral DG and then filtered (level bandwidth $1 \mathrm{~Hz}-3 \mathrm{kHz})$. The initial slope was analysed $(\mathrm{mV} / \mathrm{ms})$ and stored using our own software. Preliminary studies with strong electrical intensity stimulation $(80-150 \mu \mathrm{A}$, duration $250 \mu \mathrm{s})$ were used to obtain a detectable PEP in the DG, ${ }^{44}$ but high-frequency electrical stimulation applied to the LOT with these intensities induced kindling in all animals $(n=4)$. To prevent kindling, the current intensity was lowered (conditioned: 5-60 $\mu \mathrm{A}$, duration $50 \mu \mathrm{s}$; pseudoconditioned: 7-45 $\mu \mathrm{A}$, duration $50 \mu \mathrm{s}$ ). These current intensities were not able to produce a detectable PEP in the DG.

Single-pulse stimulation did not produce a detectable behavioral response; however, a patterned stimulation consisting of 36-ms bursts of four pulses (at $100 \mathrm{~s}^{-1}$ ) delivered with an inter-burst interval of 
Table 1. Discrimination learning of a "positive" patterned stimulation versus a "negative" odor, performed by a group of rats $(n=11)$ on five daily sessions of 60 trials each

\begin{tabular}{|c|c|c|c|c|c|}
\hline & \multicolumn{5}{|c|}{ Session (days) } \\
\hline & 1 & 2 & 3 & 4 & 5 \\
\hline Mean percentage correct & $48.02 \pm 1.61$ & $59.79 \pm 2.73$ & $73.19 \pm 2.39$ & $85.95 \pm 1.92$ & $86.39 \pm 1.9$ \\
\hline Percentage correct OMS + & $69.2 \pm 4.79$ & $92.96 \pm 1.78$ & $90.32 \pm 2.3$ & $97.65 \pm 1.07$ & $98.53 \pm 0.91$ \\
\hline Percentage correct $\mathrm{O}-$ & $26.96 \pm 2.86$ & $26.64 \pm 5.03$ & $55.17 \pm 4.94$ & $73.35 \pm 3.32$ & $73.35 \pm 3.98$ \\
\hline \multicolumn{6}{|l|}{ Latency (s) } \\
\hline $\mathrm{OMS}+$ & $5.88 \pm 0.4$ & $3.95 \pm 0.25$ & $4.02 \pm 0.24$ & $3.22 \pm 0.17$ & $2.83 \pm 0.2$ \\
\hline $\mathrm{O}-$ & $5.47 \pm 0.28$ & $5.32 \pm 0.39$ & $7.4 \pm 0.35$ & $8.56 \pm 0.2$ & $8.52 \pm 0.26$ \\
\hline
\end{tabular}

Data are shown as mean \pm S.E.M. The animals learned to not interrupt the light beam during the delivery of the negative natural odor (O - ), which resulted in an increase in mean latency and inversely for positive olfactomimetic stimulation (OMS + ). The mean latency for the negative odor never reached $10 \mathrm{~s}$, because the rats still interrupted the light beam, sometimes on every learning session. This behavior indicates that the animals paid attention to the negative odor, thereby withholding a prepotent response.

$160 \mathrm{~ms}$ elicited a robust sniffing reaction. This patterned stimulation resulted in a maximum of 50 bursts or 200 pulses on a 10-s trial if no response was made by the animal during the OMS + . Accordingly, stimulation using these parameters, sent through the stimulating electrode, was used as a cue (OMS) for discrimination learning. The electrode used to apply the OMS during the learning session was labeled the active electrode. Pilot studies revealed that discrimination learning was easier with stimulation taken as a "positive" (water reward) rather than "negative" (no water reward) cue versus a natural odor. Therefore, in Experiment 1, positive stimulation versus negative natural odor was used for the discrimination task.

In Experiment 2, we tested the possible effects of the OMS by itself in a pseudoconditioning paradigm (i.e. without behavioral training) on the DG PEP following LOT stimulation. Pseudoconditioned naive animals implanted as in Experiment 1 were given the same amount of experience (i.e. five sessions) with the patterned electrical stimulation of the LOT, natural odor, water and light flashes. Pseudoconditioned animals $(n=5)$ were prepared in the same way as trained animals until the first session. Then, from sessions 1 to 5 , they experienced explicitly unpaired presentations of patterned electrical stimulation, water, a negative odor and light flashes.

Two days before the first learning session, and before and after each learning session, 20 single biphasic pulses were delivered (one every $15 \mathrm{~s})$ to the active electrode, and the electrophysiological signals were recorded in the DG. The average of the evoked responses collected two days before the first training session and just before the beginning of the first training session served as a baseline.

The slope variable was the mean value of the rising phase of the positive slope measured between two cursors which were placed manually at the same latency individually for each animal. The onset latency was measured from the stimulus to the development of the late field potential. The peak amplitude latency was measured from the stimulus to the maximum value of the late field potential.

Statistical analysis was performed with the SPSS/PC + statistics 4.0 software marketed by SPSS. All data are presented as means \pm S.E.M. Global behavioral performance was analysed using a multivariate analysis of variance with an independent ANOVA and a NewmanKeuls post hoc comparison. The changes in electrophysiological recordings were processed by a two-tailed Wilcoxon test. The correlations between behavioral and electrophysiological data were determined by Pearson's correlation coefficient. The significance level was set at $P \leq 0.05$.

At the end of the experiment, histological verifications were performed for all rats in both experiments. When the tips of the stimulating electrodes were outside the LOT or the cell layer of the DG for the recording electrodes, the rat was excluded.

\section{RESULTS}

\section{Behavioral data}

In Experiment 1, behavioral data obtained from animals trained to discriminate between positive OMS and a negative natural odor showed that they were able to discriminate between the two cues (Table 1). During the first session, animals performed at chance level (48.02 $\pm 1.61 \%)$. Performance improved across sessions and reached the learning criterion level by session $4(85.95 \pm 1.92 \%)$, with a significant increase in correct responses from session 1 to session 2 $(P<0.05$, Newman-Keuls test $)$.

The percentage of correct responses during the first and last 10 trials of each session provides us with more information about learning (Fig. 1A). During the first session and the beginning of session 2, the animals learned to respond to both cues in order to obtain the water reward without any discrimination, i.e. without specifically associating one cue with the water reward and the other with the light. Behavioral performance was not statistically different between the beginning and the end of session 1. Animals performed at $47.27 \pm 3.33 \%$ at the beginning of the second session. A statistically significant improvement only appeared at the end of session 2, with $71.82 \pm 5.36 \%$ correct responses $(P<0.05$, Newman-Keuls test). The percentage of correct responses, during the first and last 10 trials of the last three sessions, was also statistically different from the first 10 trials of session $1(P<0.05$, Newman-Keuls test $)$.

The response latency data for the two cues showed a similar pattern (Table 1). The latencies for positive OMS and the negative natural odor at the beginning and end of all sessions (Fig. 1B) differed significantly (multivariate analysis of variance, $\left.F_{9,180}=15.55, P<0.001\right)$. During session 1 and the first 10 trials of session 2, the rats decreased their response latency in the same way for both cues. The OMS $(3.58 \pm 0.36 \mathrm{~s})$ and negative natural odor latencies $(6.52 \pm 0.8 \mathrm{~s})$ were significantly different at the end of the second session (ANOVA, $F_{1,20}=11.24, P<0.01$ ). Following the learning sessions, response latencies increased for the negative odor and decreased slightly for OMS stimuli. The difference between latencies (Fig. 1C) was statistically different when comparing the last 10 trials of session 2 to the first 10 trials of session $1(P<0.05$, Newman-Keuls test).

\section{Electrophysiological data}

Figure 2 shows an example of the electrophysiological records from conditioned and pseudoconditioned animals during five successive sessions. The conditioned animal records displayed changes in PEPs induced by patterned stimulation of the LOT used as a cue during discrimination learning.

The data on the changes in polysynaptic responses are 

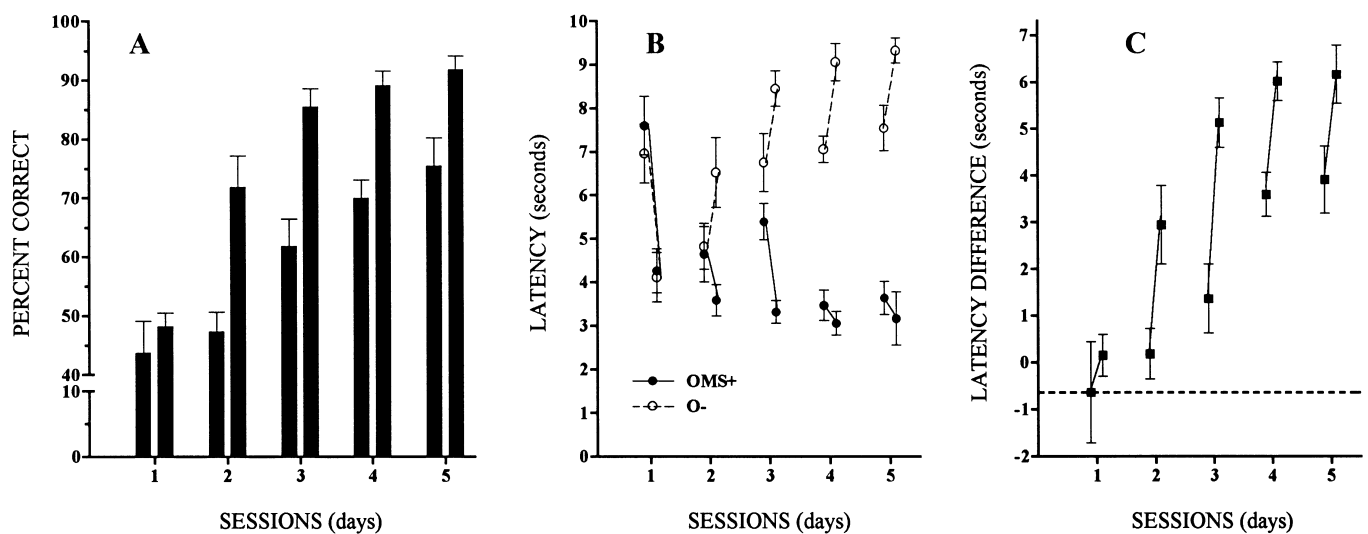

Fig. 1. Behavioral performance of rats $(n=11)$ trained to discriminate a positive electrical olfactomimetic stimulation $(\mathrm{OMS}+)$ from a natural odor $(\mathrm{O}-)$. Each pair of bars represents the mean and the S.E.M. of the first and last 10 trials of each learning session. Animals were trained in a 60-trial daily session across five days. (A) Mean percentage of correct responses for the positive (OMS) and negative (natural odor) cues. (B) Evolution of response latencies. The latency gradually decreased for OMS + and gradually increased for the natural negative odor $(\mathrm{O}-)$. (C) Difference between latencies, i.e. negative odor latency minus positive OMS latency. A significant difference was observed at the end of session $2(P<0.05$, Newman-Keuls test) for all parameters analysed.

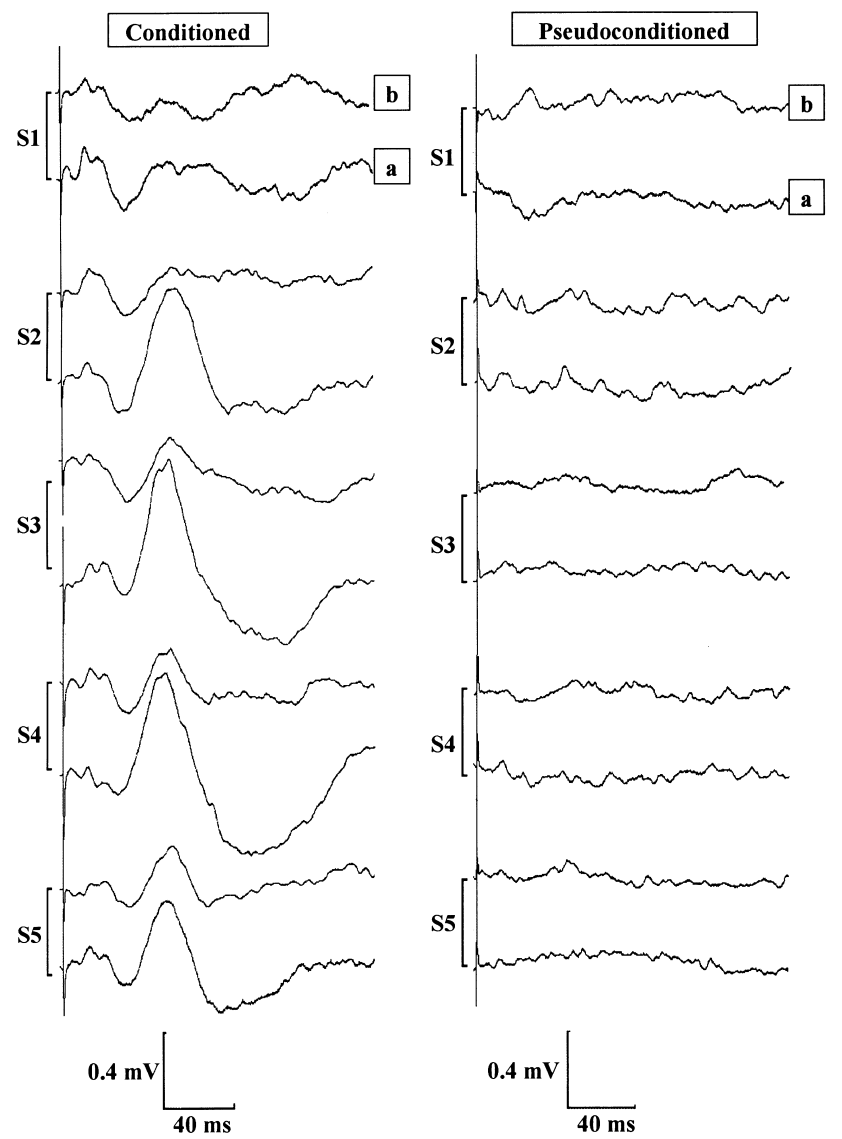

Fig. 2. Examples of the change in the PEP recorded in the granular cell layer of the DG concurrent with the learning of the association between the patterned electrical stimulation and the water reward in the conditioned and without in pseudoconditioned animals. Recording S1b is the mean baseline of the evoked potentials obtained two days before the first training session and just before session 1 (i.e. average of 60 evoked potentials). The PEP is the average of 20 single responses, before (b) and after (a) each daily session (S). A substantial increase in the PEP was observed after the end of the second session. The onset latency of the potentiated polysynaptic response was between 35 and $45 \mathrm{~ms}$.

presented in Fig. 3 (conditioned). The slope after session 1 $(0.018 \pm 0.006 \mathrm{mV} / \mathrm{ms})$ and before session $2(0.015 \pm$ $0.005 \mathrm{mV} / \mathrm{ms}$ ) was not significantly different from the

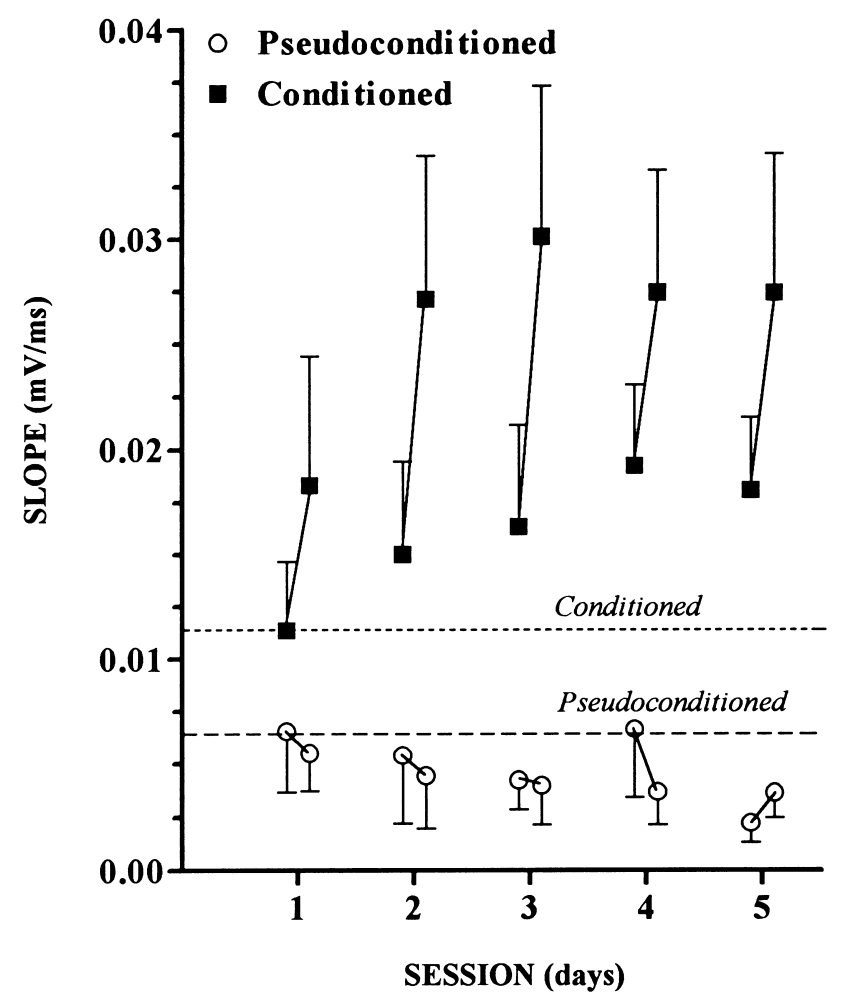

Fig. 3. Change in slope of the PEP induced by the active electrode of the conditioned $(\mathbf{\square})$ and the pseudoconditioned $(O)$ rats during the daily training sessions. Each point is the average of 20 single polysynaptic responses, except before session 1 (see caption to Fig. 2). Each pair of points represents the slope before and after each session, respectively. The data are averaged across all animals. A statistically significant increase in the slope of the PEP of the conditioned animals $(n=11)$, in comparison to the baseline value, was found at the end of session $2(P<0.03$, Wilcoxon test, twotailed). Pseudoconditioned animals $(n=5)$ received OMS, a natural odor, water and light flashes without any associations. No statistically significant increase or decrease in the slope of the active electrode was observed.

baseline. After session 2, however, a statistically significant increase appeared $(P<0.03$, Wilcoxon test, two-tailed). Electrophysiological records exhibited a considerable increase in slope (peak value: $0.027 \pm 0.007 \mathrm{mV} / \mathrm{ms}$ ) of the PEP elicited by test pulses via the active electrode. The increase in the slope was not statistically significant $24 \mathrm{~h}$ later, before 
$(0.016 \pm 0.005 \mathrm{mV} / \mathrm{ms})$ the third learning session. The electrophysiological data recorded before and after the fourth and fifth sessions showed a persistent and significant increase in the polysynaptic potential slope compared with the baseline $(P<0.05$, Wilcoxon test, two-tailed). Statistically significant intra-session changes in slope were observed during sessions 2 and $3(P<0.03$, Wilcoxon test, two-tailed). Before the third session, the slope decreased compared with the end of session $2(P<0.05$, Wilcoxon test, two-tailed), but it was not statistically different from the baseline (Fig. 3, conditioned). A statistically significant decrease was also observed before the fifth session compared with the end of the fourth session $(P<0.05$, Wilcoxon test, two-tailed).

In Experiment 2, when the patterned stimulations were applied to the LOT without any learning context (pseudoconditioned), there was a non-statistically significant trend towards a decrease in the slope of the PEP across the five sessions (Fig. 3, pseudoconditioned).

\section{Correlations}

In order to correlate the changes in the polysynaptic responses recorded in the DG prior to and just after a training session with the corresponding behavioral data, the first 10 trials and the last 10 trials of each training session were considered.

A highly significant correlation existed between the percentage of correct responses to both cues and the slope variations of the PEP before and after each session (Fig. 4A), across all sessions ( $r=0.315, n=110, P<0.001)$.

A correlation appeared, across all sessions, between the slope of the PEP and the percentage of correct responses to $\mathrm{OMS}+(r=0.2781, n=110, P<0.01)$, and the percentage of correct responses to $0-(r=0.2134, n=110, P<0.05)$ independently (Fig. 4B, C).

A highly significant correlation existed (Fig. 4D) between the latency differences and the slope variations of the PEP before and after each session, across all sessions $(r=0.2704, n=110, P<0.01)$. There was a correlation between the variations of the slope and the latencies to $\mathrm{OMS}+$ (Fig. 4E), across all sessions $(r=-0.2527$, $n=110, P<0.01)$. Latency to $\mathrm{O}-$ decreased from the beginning of the first session to the beginning of the second session, before increasing until the last session. For this reason, a correlation was calculated between the variation of the slope and the latency to $\mathrm{O}-$, from the end of session 2 to the last session (Fig. 4F). A correlation existed between the two parameters across these sessions $(r=0.2067, n=77$, $P<0.05)$. Pearson's coefficients for all individual sessions exhibited no significant correlation between the two parameters (PEP slope/O - latency).

When comparing individual sessions, the percentage of correct responses on session 2 was statistically different to that on session $1(P<0.05$, Newman-Keuls test $)$. Specifically, there was no change during the first 10 trials of session 2 and a statistically significant increase on the last 10 trials with $71.82 \pm 5.36 \%(P<0.05$, Newman-Keuls test $)$. Moreover, the electrophysiological results show a statistically significant increase in the slope of the PEPs after the end of session 2 compared with the slope before session 1 and 2 or after session 1. Surprisingly, in spite of this similarity, Pearson's coefficient showed no correlation between the percentages of correct responses of session 2 and the slope values before and after this session $(r=0.229, n=22$, not significant). Pearson's coefficients for all individual sessions exhibited no significant correlation between the two parameters (PEP slope/percentage correct).

\section{DISCUSSION}

This report provided electrophysiological data concerning the chronology of polysynaptic potentials recorded in the DG during an associative task.

In these experiments, it was demonstrated that a patterned electrical stimulation can be used as an artificial discriminative cue $(\mathrm{OMS}+)$ versus a natural odor $(\mathrm{O}-)$, since the beginning of the training session. The OMS is not an electrical odor, but only an electrophysiological technique enabling one to activate the same tracts as activated by a natural odor. The patterned electrical stimulation of the LOT elicited a robust sniffing reaction and allowed us to obtain similar learning curves obtain with the discrimination of two natural odors. ${ }^{35}$ We have no evidence that OMS resembles an olfactory stimulus, but the learning curve seems to indicate that learning to respond to OMS resembles olfactory learning. Thus, these stimulations were denominated olfactory mimetic stimulation, as was reported previously. ${ }^{35,36}$ At the beginning of the first session, the response latencies for the two cues were not different (Fig. 1B). During this session, the rats decreased their response latencies in the same way for both cues, resulting in a non-significant difference between the two responses latencies over the last 10 trials. At the beginning of the second session, the response latencies for the two cues did not differ before divergence. The fact that the response latency to the negative natural odor decreased before increasing showed that the rats paid attention to the negative natural odor to perform the task. Moreover, it was observed that rats responded to the negative natural odor sometimes even after mastering the task (i.e. in sessions 4 and 5), and there is also a correlation between the evolution of the electrophysiological data and the evolution of the behavioral performances with the negative natural odor.

A large, significant increase in the field potential of the polysynaptic responses evoked by the active electrode appeared just after the end of session 2. In hippocampal slice preparations, high-frequency electrical stimulations applied according to the theta rhythm, similar to our OMS, have been shown to induce LTP. ${ }^{25}$ The early polysynaptic potentiation observed in the DG is not due to stimulation by itself, because no change in the field potential of the polysynaptic responses was observed in pseudoconditioned animals. These results suggest that polysynaptic potentiation is specific to the neural components activated by the OMS stimulation through the active electrode only when OMS + is associated with a water reward. Moreover, this provides arguments in favor of an early and rapid activation of the hippocampus, allowing for the association between the stimulus and the reward, i.e. the OMS and the water.

The electrophysiological bipolar records show a predominantly positive-going, slow, extracellular field potential in the DG. Field potential theory assumes that an extracellular positive potential represents an outward current generated by a sink or an inward current located close to or far from the recording tip. ${ }^{26}$ In the present study, the electrophysiological stimulation-record assembly does not allow us to determine 

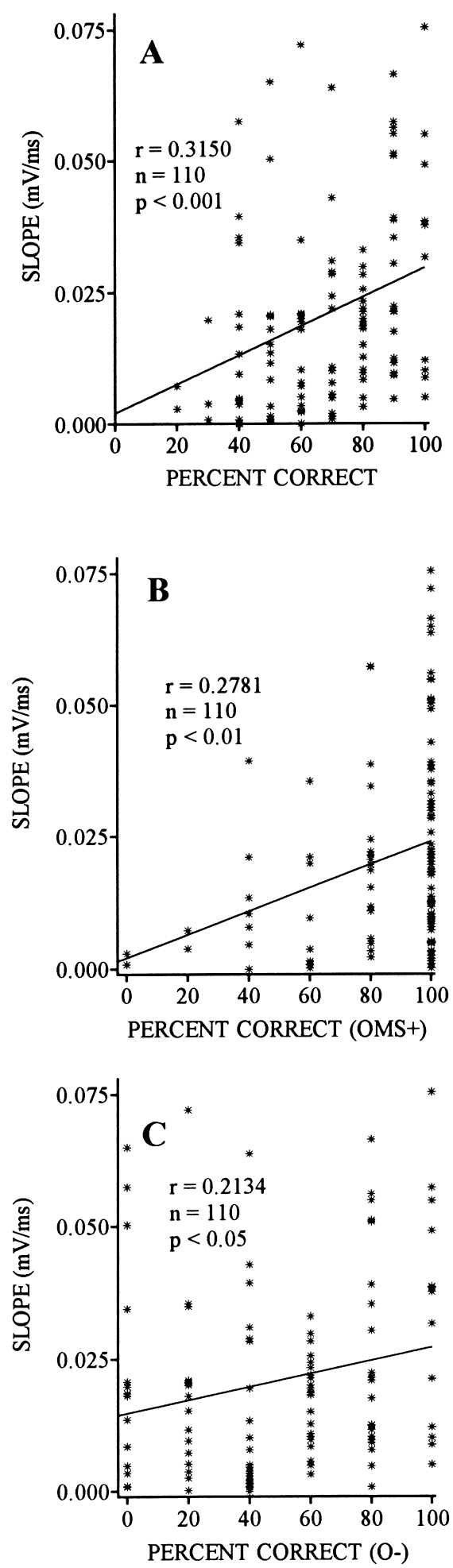
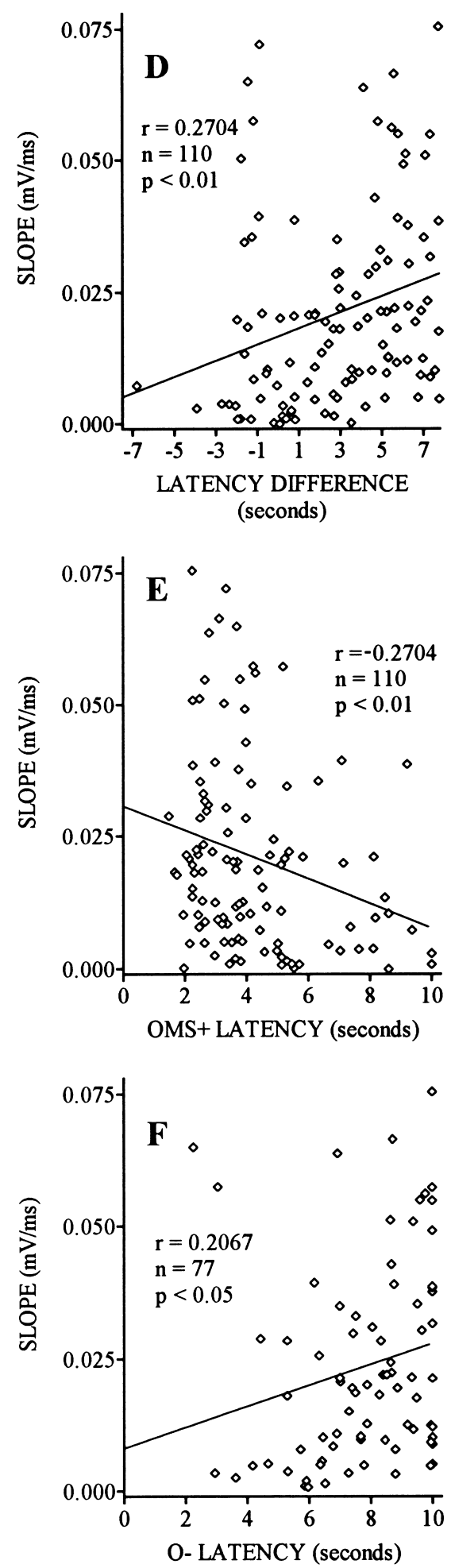

Fig. 4. Relationship between the change in slope $(\mathrm{mV} / \mathrm{ms})$ of the PEP and different behavioral data. The slope is the average of 20 evoked potentials elicited by single pulses collected prior to and after the training sessions, and paired to behavioral data of the first and last 10 trial blocks in the same session, respectively. In both graphs, individual data of the 11 rats are reported. (A) Pearson coefficient correlation for the five training sessions between the change in slope and the percentage of correct responses for both cues. (B, C) Correlation between the change in slope and the percentage of correct responses to OMS + (B) and to $\mathrm{O}-(\mathrm{C})$, respectively. (D) Pearson coefficient correlation between change in slope and the latency difference (O - minus OMS + ). (E, F) Correlation between the change in slope and the response latency to OMS $+(\mathrm{E})$ and to $\mathrm{O}-(\mathrm{F})$.

the exact sink activity. However, the bipolar intra-DG record suggests strongly a local DG origin of the PEP.

The onset latency of the PEP which exhibits a potentiation in the DG is of particular interest. Earlier studies ${ }^{44}$ and our observations during the implantation have shown that a single electrical test stimulation of the LOT induces a PEP in the DG with an onset latency of 14-20 ms. However, the onset latency of the polysynaptic potential, after potentiation, was between 35 and $45 \mathrm{~ms}$ in our work, with a peak amplitude latency of 60-70 ms. The main consistent explanation of the 


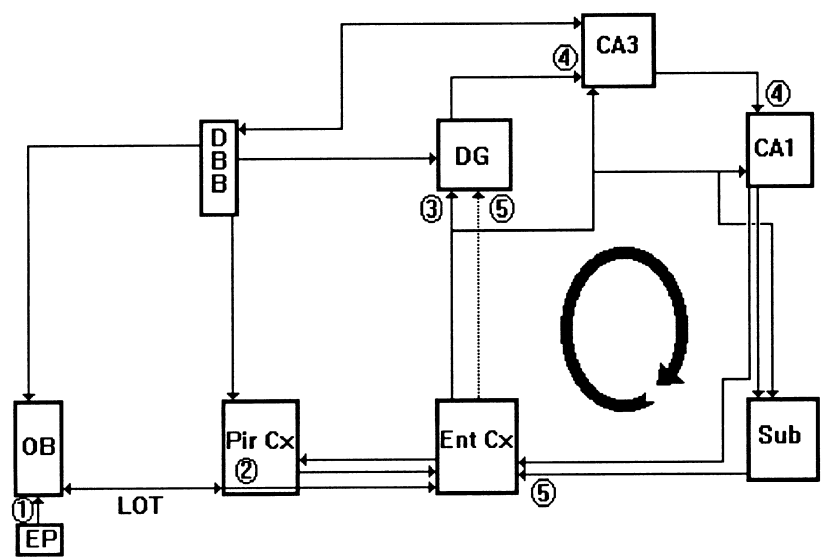

Fig. 5. Schematic representation of the main connections of the olfactohippocampal loop. The perception of odor activates the glomeruli of the olfactory bulb (1). The olfactory information is sent to the piriform and entorhinal cortices via the lateral olfactory tract (2). An LTP can be induced in the piriform cortex during the memorization of the meaning of an olfactory cue. ${ }^{31}$ From the entorhinal cortex, the perforant pathway provides an important afferent to the hippocampus. The olfactory information is conveyed via the lateral perforant pathway ${ }^{38}$ to the DG (3). The information is sent through the classical trisynaptic hippocampal pathway to the CA3, CA1 and subiculum (4). The projections from the CA1 and the subiculum to the entorhinal cortex (5) can reactivate the DG after information processing by the hippocampus. The potentiation of the PEP in the DG may reflect the activation of these reactivating hippocampal loops. The hippocampal efferent projection could also modulate the synaptic transmission and the storage of olfactory information in the olfactory bulb and piriform cortex via the diagonal band of Broca. Arrows indicate the main direction of the current loop flow. CA1, ammonic field 1; CA3, ammonic field 3; DBB, diagonal band of Broca; Ent Cx, entorhinal cortex; EP, olfactory epithelium; OB, olfactory bulb; Pir Cx, piriform cortex; Sub, subiculum. Modified from De Curtis et al. ${ }^{8}$

PEP onset latency, based on the time conduction data in the literature, ${ }^{41,42,44,46}$ is a possible DG reactivation after one complete hippocampal loop (Fig. 5). De Curtis et al. ${ }^{8}$ have demonstrated the existence of "reverberant activation of the entorhinal (cortex)-hippocampal-entorhinal (cortex) circuit following a single electrical stimulation of the LOT", in vitro. Our data are consistent with this kind of sequential activation, which could provide reactivation of hippocampo-cortico-hippocampal loops, enabling the modification of the mnemonic engram on different structures of the olfactohippocampal pathway, as discussed in the next section. Moreover, a similar kind of transfer and storage of information has been shown to occur between the CA1 and the prefrontal cortex during classical conditioning in the rat. ${ }^{10}$

In previous experiments, Roman et al. ${ }^{36}$ demonstrated that a gradual form of LTP in the piriform cortex was correlated with an improvement in behavioral performance in animals without any previous training using the same technical approach (i.e. prior to the fourth session). However, several studies have shown that piriform cortex LTP can only be induced in slices when it is disconnected from surrounding limbic structures, ${ }^{13,18-20}$ or after previous training with two natural odors in which animals learned the protocol of the olfactory task before the use of the electrical cue. ${ }^{35}$ An explanation that is consistent with the literature on learning and memory ${ }^{38,39}$ would be that the limbic circuits related to the olfactory cortex will have an important influence on the target cells in the piriform cortex..$^{20,21,35-37}$ The association between the cue and reward could be processed, at least in part, by this limbic circuit, which consequently would allow the suppression of the active inhibition on piriform cortex neurons and the long-term change of selective cortical synapses solicited by the LOT inputs.

Our present data show that the hippocampus is activated early during the learning of the association between cues (artificial cue or natural odor) and their respective rewards (water or light flash). This observation is in line with a differential dynamic activation of cortical and limbic structures during active learning behaviors along the olfactohippocampal loop. The onset latency of the potentiated response in the DG suggests hippocampal processing of olfactory information before DG reactivation via the entorhinal cortex. This hypothesis is strongly reinforced by the entorhinalhippocampal interactions revealed by Iijima et al. ${ }^{16}$ Moreover, Bartesaghi et al. ${ }^{2}$ showed recently that "the entorhinal-hippocampal-entorhinal loop transforms a linear input into a non-linear, almost all-or-none output and that the DG is the critical site where the transformation occurs". This finding is in agreement with our data, which provided evidence of an all-or-none, long-latency polysynaptic potentiated potential recorded in the DG during learning. It is an all-or-none-like phenomenon because the potentiation appears only at the end of session 2 and not progressively. Indirectly, the hippocampus could influence the synaptic transmission in the olfactory bulb ${ }^{22,23}$ and piriform cortex, ${ }^{12,14}$ and the storage of information in both structures ${ }^{20,31}$ via the horizontal diagonal band of Broca, which contains GABA$\operatorname{ergic}^{9,29}$ and cholinergic ${ }^{17}$ cells.

An alternative explanation for a delayed transmission to the DG includes processing in the piriform cortex itself. The reader will find an extensive review of the modulatory loops in Lynch and Granger ${ }^{28}$ and Eichenbaum et al. ${ }^{11}$

\section{CONCLUSIONS}

The polysynaptic potentiation recorded in the DG suggests an early activation of the hippocampus during the learning of an associative task (i.e. after the second session), contrary to a later and gradual potentiation of synapses in the piriform cortex $^{36}$ using the same task (i.e. prior to the fourth session). Further studies will be needed to determine whether the polysynaptic potentiation recorded in the DG has the monosynaptic characteristics of an LTP-like phenomenon. Moreover, additional electrophysiological experiments without behavioral demand, using current source density mapping, will be necessary to identify the exact sources and sinks in the hippocampal loops. Such studies should allow us to determine the site(s) and the nature of the modifications occurring in the limbic structures, and would underline the importance of the polysynaptic reactivating loop through the entorhinal cortex.

Acknowledgements-We would like to thank Alain Bouquerel for technical assistance and Michelle Bauget for expert secretarial assistance. This work was supported by the CNRS and a grant from the DRET.

\section{REFERENCES}


2. Bartesaghi R., Gessi T. and Migliore M. (1995) Input-output relations in the entorhinal-hippocampal-entorhinal loop: entorhinal cortex and dentate gyrus. Hippocampus 5, 440-451.

3. Berry C. M., Hagamen W. D. and Hinsey J. C. (1978) Distribution of potentials following stimulation of olfactory bulb in cat. J. Neurophysiol. 15, 139-148.

4. Bliss T. V. P. and Gardner-Medwin A. R. (1973) Long-lasting potentiation of synaptic transmission in the dentate area of the anaesthetized rabbit following stimulation of the perforant path. J. Physiol. 232, 357-374.

5. Bliss T. V. P. and Lømo T. (1973) Long-lasting potentiation of synaptic transmission in the dentate area of anaesthetized rabbit following stimulation of the perforant path. J. Physiol. 232, 331-356.

6. Bloch V. and Laroche S. (1984) Facts and hypotheses related to search for engram. In Neurobiology of Learning and Memory (eds Lynch G., McGaugh J. L. and Weinberger N. M.), pp. 249-260. Guilford, New York.

7. Chaillan F. A., Devigne C., Diabira D., Khrestchatisky M., Roman F. S., Ben-Ari Y. and Soumireu-Mourat B. (1997) Neonatal $\gamma$-ray irradiation impairs learning and memory of an olfactory associative task in adult rats. Eur. J. Neurosci. 9, 884-894.

8. De Curtis M., Pare D. and Llinas R. R. (1991) The electrophysiology of the olfactory-hippocampal circuit in the isolated and perfused adult mammalian brain in vitro. Hippocampus 1, 341-354.

9. Divac I. (1975) Magnocellular nuclei of the basal forebrain project to neocortex, brain stem and olfactory bulb. Review of some functional correlates. Brain Res. 93, 385-398.

10. Doyère V., Burette F., Redini-Del Negro C. and Laroche S. (1993) Long-term potentiation of hippocampal afferents and efferents to prefrontal cortex: implications for associative learning. Neuropsychologia 31, 1031-1053.

11. Eichenbaum H., Otto T. A., Wible C. G. and Piper J. M. (1991) Building a model of the hippocampus in olfaction and memory. In A Model System for Computational Neuroscience: Olfaction (eds Davis J. L. and Eichenbaum H.), pp. 167-210. MIT, Cambridge, MA.

12. Gervais R., Mouly A. M., Elaagouby K. and Levy F. (1990) Olfactory bulb plasticity. In Chemosensory Information Processing (ed. Schild D.), pp. 191-200. Springer, Berlin.

13. Hasselmo M. E. and Bower J. M. (1990) Afferent and association fiber differences in short-term potentiation in piriform (olfactory) cortex of the rat. J. Neurophysiol. 64, 179-190.

14. Hasselmo M. E., Wilson M. A., Anderson B. P. and Bower J. M. (1990) Associative memory function in piriform (olfactory) cortex: computational modeling and neuropharmacology. In Cold Spring Harbor Symposium on Quantitative Biology: The Brain, Vol. 55, pp. 599-610. Cold Spring Harbor Laboratory, Cold Spring Harbor, NY.

15. Hjorth-Simonsen A. (1971) Hippocampal efferents to the ipsilateral entorhinal area: an experimental study in the rat. J. comp. Neurol. 142, 417-438.

16. Iijima T., Witter M. P., Ichikawa M., Tominaga T., Kajiwara R. and Matsumoto G. (1996) Entorhinal-hippocampal interactions revealed by real-time imaging. Science 272, 1176-1179.

17. Jacobowitz D. M. and Creed G. J. (1983) Cholinergic projection sites of the nucleus of tractus diagonalis. Brain Res. Bull. 10, 365-367.

18. Jung M. W., Larson J. and Lynch G. (1990) Long-term potentiation of monosynaptic EPSPs in rat piriform cortex in vitro. Synapse 6, $279-283$.

19. Jung M. W., Larson J. and Lynch G. (1990) Role of NMDA and non-NMDA receptors in synaptic transmission in rat piriform cortex. Expl Brain Res. 82, $451-455$.

20. Kanter E. D. and Haberly L. B. (1990) NMDA-dependent induction of long-term potentiation in afferent and association fiber systems of piriform cortex in vitro. Brain Res. 55, 175-179.

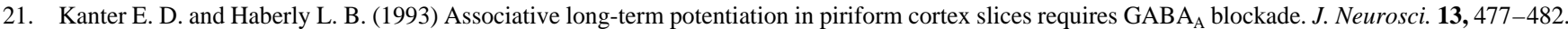

22. Kunze W. W. A., Shafton A. D., Kemm R. E. and McKenzie J. S. (1990) Intracellular responses of olfactory bulb neurons to basal forebrain stimulation. Proc. Aust. physiol. pharmac. Soc. 21, 53.

23. Kunze W. W. A., Shafton A. D., Kemm R. E. and McKenzie J. S. (1991) Effects of stimulating the nucleus of the horizontal limb of the diagonal band on single unit activity in the olfactory bulb. Neuroscience 40, 21-27.

24. Laroche S., Jay T. M. and Thierry A. M. (1990) Long-term potentiation in the prefrontal cortex following stimulation of hippocampal CA1/subicular region. Neurosci. Lett. 114, 184-190.

25. Larson J., Wong D. and Lynch G. (1986) Patterned stimulation at the theta frequency is optimal for induction of long-term potentiation. Brain Res. 368, $347-350$.

26. Leung L. W. S. (1990) Field potentials in the central nervous system: recording, analysis, and modeling. In Neurophysiological Techniques: Applications to Neural Systems (eds Boulton A. A., Baker G. B. and Vanderwolf C. H.), pp. 277-312. Humana, Clifton, NJ.

27. Luskin M. B. and Price J. L. (1982) The topographic organization of associational fibers of the olfactory system in the rat, including centrifugal fibers to the olfactory bulb. J. comp. Neurol. 216, 264-291.

28. Lynch G. and Granger R. (1991) Serial steps in memory processing: possible clues from studies of plasticity in the olfactory-hippocampal circuit. In $A$ Model System for Computational Neuroscience: Olfaction (eds Davis J. L. and Eichenbaum H.), pp. 141-165. MIT, Cambridge, MA.

29. Macrides F., Davis B. J., Youngs W. M., Nadi N. S. and Margolis F. F. (1981) Cholinergic and catecholaminergic afferents to the olfactory bulb in the hamster: a neuroanatomical, biochemical and histochemical investigation. J. comp. Neurol. 203, 495-514.

30. Miller R. (1989) Cortico-hippocampal interplay: self-organizing phase-locked loops for indexing memory. Psychobiology 17, 115-128.

31. Mouly A. M., Gervais R. and Holley A. (1990) Evidence for the involvement of rat olfactory bulb in processes supporting long-term olfactory memory. Eur. J. Neurosci. 2, 978-984.

32. Okada Y. and Miyamoto T. (1989) Formation of long-term potentiation in superior colliculus slices from guinea pig. Neurosci. Lett. 96, 108-113.

33. Paxinos G. and Watson C. (1986) The Rat Brain in Stereotaxic Coordinates, 2nd edn. Academic, San Diego, CA.

34. Racine R. J., Milgram N. M. and Hafner S. (1983) Long-term potentiation phenomena in the rat limbic forebrain. Brain Res. $260,217-231$.

35. Roman F., Staubli U. and Lynch G. (1987) Evidence for synaptic potentiation in a cortical network during learning. Brain Res. 418, 221-226.

36. Roman F. S., Chaillan F. A. and Soumireu-Mourat B. (1993) Long-term potentiation in rat piriform cortex following discrimination learning. Brain Res. 601, 265-272.

37. Roman F. S., Simonetto I. and Soumireu-Mourat B. (1993) Learning and memory of odor-reward association: selective impairment following horizontal diagonal band lesions. Behav. Neurosci. 107, 72-81.

38. Scoville W. B. and Milner B. (1957) Loss of recent memory after bilateral hippocampal lesions. J. Neurol. Neurosurg. Psychiat. $20,11-21$.

39. Squire L. R. and Zola-Morgan S. (1991) The medial temporal lobe memory system. Science 253, 1380-1386.

40. Stripling J. S. and Patneau D. K. (1985) Selective long-term potentiation in the pyriform cortex. Soc. Neurosci. Abstr. $11,779$.

41. Van Groen T., Lopes Da Silva F. H. and Wadman W. J. (1987) Synaptic organization of olfactory inputs on local circuit in the entorhinal cortex: a current source density analysis in the cat. Expl Brain Res. 67, 615-622.

42. Van Groen T. and Lopes Da Silva F. H. (1986) Organization of the reciprocal connections between the subiculum and the entorhinal cortex in the cat. II. An electrophysiological study. J. comp. Neurol. 251, 111-120.

43. Verzeano M. (1977) The activity of neuronal networks in memory consolidation. In Neurobiology of Sleep and Memory (eds Drucker-Colin R. R. and McGaugh J. L.), pp. 75-97. Academic, New York.

44. Wilson R. C. and Steward O. (1978) Polysynaptic activation of the dentate gyrus of the hippocampal formation: an olfactory input via entorhinal cortex. Expl Brain Res. 33, 523-534.

45. Witter M. P., Groenewegen H. J., Lopes Da Silva F. H. and Lohman A. H. M. (1989) Functional organization of the extrinsic and intrinsic circuitry of the parahippocampal region. Prog. Neurobiol. 33, 161-253. 
46. Yeckel M. F. and Berger T. H. (1990) Feedforward excitation of the hippocampus by afferents from the entorhinal cortex: redefinition of the role of the trisynaptic pathway. Proc. natn. Acad. Sci. U.S.A. 87, 5832-5836.

47. Zaborszky L., Carlsen J., Brashear H. R. and Heimer L. (1986) Cholinergic and GABAergic afferents to the olfactory bulb in the rat with special emphasis on the projection neurons in the nucleus of the horizontal limb of the diagonal band. J. comp. Neurol. 243, 488-509.

(Accepted 8 June 1999) 